\title{
Surgical Treatment of Renal Cell Cancer Liver Metastases: A Population-Based Study
}

\author{
Anthony T. Ruys, $\mathrm{MD}^{1}$, Pieter J. Tanis, $\mathrm{MD}^{1}$, Nagtegaal D. Iris, $\mathrm{MD}^{2}$, Peter van Duijvendijk, $\mathrm{MD}^{3}$, \\ Cornelis Verhoef, $\mathrm{MD}^{4}$, Robert J. Porte, $\mathrm{MD}^{5}$, and Thomas M. van Gulik, MD, $\mathbf{P h D}^{1}$ \\ ${ }^{1}$ Department of Surgery, Academic Medical Centre, University of Amsterdam, Amsterdam, The Netherlands; ${ }^{2}$ Department \\ of Pathology, Radboud University Nijmegen Medical Center, Nijmegen, The Netherlands; ${ }^{3}$ Department of Surgery, \\ Radboud University Nijmegen Medical Center, Nijmegen, The Netherlands; ${ }^{4}$ Department of Surgery, Erasmus MC-Daniel \\ den Hoed Cancer Centre, Rotterdam, The Netherlands; ${ }^{5}$ Department of Surgery, University Medical Centre Groningen, \\ Groningen, The Netherlands
}

\begin{abstract}
Background. To evaluate outcomes of surgical treatment in patients with hepatic metastases from renal-cell carcinoma in the Netherlands, and to identify prognostic factors for survival after resection. Renal-cell carcinoma has an incidence of 2,000 new patients in the Netherlands each year (12.5/100,000 inhabitants). According to literature, half of these patients ultimately develop distant metastases with $20 \%$ involvement of the liver. Resection of renal-cell carcinoma liver metastases (RCCLM) is performed in only a minority of patients. Hence, little is known about outcome of resectable RCCLM.

Methods. Patients were retrieved from local databases of theNetherlands Task Force for Liver Surgery (14 centers) and from the Dutch collective pathology database. Survival and prognostic factors were determined by Kaplan-Meier analysis and log rank test.

Results. Thirty-three patients were identified who underwent resection $(n=29)$ or local ablation $(n=4)$ of RCCLM in the Netherlands between 1990 and 2008. These patients comprise $0.5 \%$ to $1 \%$ of the total population of
\end{abstract}

This study was conducted for the Dutch Study Group for Liver Surgery. The collaborators of the study group are listed in Appendix This manuscript was presented in part at the Annual Meeting of the European Surgical Association (ESA), Budapest, Hungary, May 7-8, 2010.

(C) The Author(s) 2011. This article is published with open access at Springerlink.com

First Received: 24 November 2010;

Published Online: 23 February 2011

T. M. van Gulik, MD, PhD

e-mail: T.M.vanGulik@amc.uva.nl patients diagnosed with RCCLM in that period. There was no operative mortality. The overall survival at 1,3 , and 5 years was 79,47 , and $43 \%$, respectively. Metachronous metastases $(n=23, P=0.03)$ and radical resection $(n=19, P<0.001)$ were statistically significant prognosticators of overall survival. Size $<50 \mathrm{~mm}(n=18$, $P=0,54)$, solitary metastases $(n=19, P=0.93)$, and presence of extrahepatic metastases $(n=11, P=0.28)$ did not have a statistically significant impact on survival. Conclusions. The favorable 5-year survival rate of $43 \%$ without operative mortality as found in this nationwide study indicates that selected patients with RCCLM can benefit from surgical treatment.

In the Netherlands, with a population of 16 millions, 2000 people are diagnosed with renal-cell carcinoma (RCC) each year with a corresponding incidence of 12.5 per 100,000 inhabitants. ${ }^{1}$ At presentation, 25 to $30 \%$ of patients with RCC have distant metastases, and another third develop systemic recurrence after primary tumor resection. ${ }^{2}$ Prognosis is poor in patients with metastatic RCC, with 5-year survival ranging from 5 to $10 \% .{ }^{3}$ Surgery is still the only curative treatment, while RCC is only little affected by radiotherapy or chemotherapy. ${ }^{4}$ Recently, molecularly targeted therapy has become available for advanced RCC and showed overall survival benefit in large multicenter trials. ${ }^{5,6}$

In addition to the role of surgery in primary therapy, patients with distant metastases of RCC that are solitary or restricted to one organ are also candidates for surgical treatment. Outcomes of surgery for metastatic RCC have most thoroughly been investigated for pulmonary 
localizations because the lungs are a preferential metastatic site. ${ }^{7}$ The liver is less often involved and infrequently is the only site of metastatic RCC. ${ }^{8}$ Development of hepatic metastases is generally considered a poor prognostic factor and is frequently a predictor of more widespread disease. ${ }^{9}$ This is why such patients are only incidentally referred for liver resection, and consequently, there is little available literature on this topic. Patients with RCC liver metastases (RCCLM) are often pooled in series with hepatic metastases that are not of colorectal or neuroendocrine origin. This group includes liver metastases from genitourinary malignancies, sarcomas, breast cancer, melanoma, and other primary tumors. Tumor biology and clinical behavior vary greatly among these different malignancies.

The objective of this study was to determine population characteristics, survival, and prognostic factors in patients with RCCLM who underwent local treatment, either by surgery or ablative techniques, in the Netherlands.

\section{MATERIALS AND METHODS}

\section{Patients}

To identify a complete cohort of patients with RCCLM who had been surgically treated in the Netherlands, a search in the national histopathology database, PALGA, was performed. ${ }^{10}$ PALGA (Pathologisch Anatomisch Landelijk Geautomatiseerd Archief; Pathological Anatomy National Automated Archive) is a nationwide network and archive that has been set up in the Netherlands to facilitate the optimal use of histopathology and cytopathology data. PALGA has been available since 1971, and all 64 histopathology and cytopathology laboratories in the Netherlands contribute to it. It currently contains approximately 42 million excerpts from nearly 10 million patients. $^{10}$

This study was conducted under the direction of the Netherlands Task Force for Liver Surgery. All members were sent a letter that asked them to check their local databases for surgically treated patients with RCCLM. In addition, patient information obtained by the search in PALGA was provided to aid in this process. A specific questionnaire designed to acquire a variety of patient characteristics concerning primary tumor, metastases, treatment, and outcome was attached to this letter. One of the investigators (A.T.R.) visited some of the hospitals to examine and collect the data. Survival data were obtained from the local hospitals and were updated if necessary by contacting primary care physicians.

Patients with direct ingrowth of the primary tumor in the liver or ingrowth of peritoneal metastases in the liver were excluded from this analysis because of probable different tumor biology and patient survival. For the same reason, patients with nephroblastoma as primary tumor were excluded. ${ }^{9}$

A total of 37 patients with RCCLM were identified by the described search strategy. Data from four of these patients could not be retrieved as a result of unavailability of the patients' records in the hospitals concerned. This was likely the result of the long time period between treatment and data retrieval (up to 19 years). This resulted in a study population of 33 patients treated in a 19-year period between 1990 and 2008. Population characteristics are displayed inTable 1. Data were obtained from a total of 14 hospitals, including 7 university hospitals and 7 referring hospitals.

\section{Statistical Analysis}

Overall and disease-free survival were determined according to the Kaplan-Meier method. Potential prognosticators of overall survival were evaluated by univariate analysis by the log rank test. The univariate tested variables were chosen on the basis of reported prognostic factors in the literature on metastatic RCC and colorectal liver metastases: patient sex and age, site of primary tumor, characteristics of RCCLM (number, size, metachronous or synchronous, and disease-free interval), presence of extrahepatic disease, and completeness of resection. A multivariate analysis was not feasible in this study as a result of the small sample size. $P$ values of $<0.05$ were considered statistically significant. The data were analyzed with SPSS software, version 16.0 (SPSS, Chicago, IL).

\section{RESULTS}

\section{Population Characteristics}

Histopathology of the primary tumor could be retrieved in 28 patients $(84 \%)$, and showed clear-cell carcinoma in most patients (63\%). Most RCCLM were metachronous (70\%), with a median interval from nephrectomy of 50 (range 7-360) months. RCCLM were multiple in 14 patients $(43 \%)$, with an upper limit of 19 . There was evidence of extrahepatic disease in 11 patients (33\%). These metastases were surgically treated with curative intent before liver resection, or were synchronously discovered at laparotomy and subsequently resected. The extrahepatic metastases included metastases to vagina, omentum, bile duct, diaphragm, adrenal gland, gallbladder, and lung. The patient with metastases to the bile duct was previously described in the literature. ${ }^{11}$ Twelve patients received additional systemic treatment including chemotherapy, 
TABLE 1 Population characteristics of 33 patients who underwent surgical or local ablative resection of renal-cell carcinoma liver metastases

\begin{tabular}{|c|c|}
\hline Factor & Value $^{\mathrm{a}}$ \\
\hline \multicolumn{2}{|l|}{ Sex } \\
\hline Male & $16(48)$ \\
\hline Female & $17(52)$ \\
\hline Age (y), median (range) & $61(20-77)$ \\
\hline \multicolumn{2}{|l|}{ Histology } \\
\hline Clear cell & $21(64)$ \\
\hline Chromophobe & $3(9)$ \\
\hline Papillary & $3(9)$ \\
\hline Other/unknown & $6(18)$ \\
\hline \multicolumn{2}{|l|}{ Metastases } \\
\hline \multicolumn{2}{|l|}{ Time } \\
\hline Synchronous & $10(30)$ \\
\hline Metachronous (7-360 mo) & $23(70)$ \\
\hline \multicolumn{2}{|l|}{ Symptomatic } \\
\hline Yes & $9(45)$ \\
\hline No & $11(55)$ \\
\hline \multicolumn{2}{|l|}{ Size } \\
\hline$\leq 50 \mathrm{~mm}$ & $18(60)$ \\
\hline$>50 \mathrm{~mm}$ & $12(40)$ \\
\hline \multicolumn{2}{|l|}{ Number } \\
\hline Solitary & $19(58)$ \\
\hline Multiple (1-19) & $14(42)$ \\
\hline \multicolumn{2}{|l|}{ Localization } \\
\hline Left liver lobe & $10(32)$ \\
\hline Right liver lobe & $20(62)$ \\
\hline Bilateral lobes & $2(6)$ \\
\hline \multicolumn{2}{|l|}{ Extrahepatic disease } \\
\hline Yes & $11(33)$ \\
\hline No & $22(67)$ \\
\hline \multicolumn{2}{|l|}{ (Neo)adjuvant therapy } \\
\hline Immunotherapy & $7(21)$ \\
\hline Chemotherapy & $3(9)$ \\
\hline Molecularly targeted therapy & $3(9)$ \\
\hline
\end{tabular}

$\overline{{ }^{a}}$ Values are expressed as $n(\%)$ unless otherwise indicated. Missing numbers are a result of unknown data

immunotherapy (interferon and interleukin-2), and molecularly targeted therapy (sunitinib and sorafenib).

\section{Operative Data}

The surgical treatment performed in these patients included 8 metastasectomies (24\%), 10 segmentectomies (30\%), 4 left hemihepatectomies (12\%), 6 right hemihepatectomies (18\%), 1 extended right hemihepatectomy, and 8 radiofrequency ablations (RFA). RFA was performed in addition to resection in 4 patients and was the only treatment modality in another 4 patients. All RFA procedures were performed during laparotomy. Resection margin was tumor negative in $19(76 \%)$ of 25 patients who underwent resection, as defined by removal of all macroscopically detectable disease and microscopically clear resection margins. Patients who underwent RFA as solitary treatment or in combination with resection were excluded from this analysis. There was no operative mortality, and postoperative complications developed in 6 patients (18\%). These were classified as major complication (Dindo-Clavien grade IV) in 2 patients $(6 \%){ }^{12}$ This postoperative morbidity consisted of lung embolism, atrial fibrillation, intra-abdominal hemorrhage, reversible liver failure, pleural fluid, and intra-abdominal abscess. Relaparotomy was only required in the patient who had active postoperative bleeding.

\section{Survival}

Complete survival data could be retrieved from all patients. At the end of the study, 17 patients (52\%) had died. Of the 16 patients (48\%) alive, 11 had evidence of recurrent disease, either hepatic or extrahepatic. The time to recurrence ranged from 1 to 54 months, with a median of 10 months. The 1-, 3-, and 5-year disease-free survival rates were 49,18 , and $11 \%$, respectively (Fig. 1). None of the patients with recurrent hepatic metastases underwent repeat liver resection. One patient was diagnosed with metastases to the lungs after 33 months. He survived two consecutive metastasectomies of the lungs, and is still alive after 212 months. Median survival of patients with recurrent disease was 23 (range 3-212) months.



FIG. 1 Overall survival and disease-free survival after surgical treatment in patients who underwent resection of renal-cell carcinoma liver metastases 
TABLE 2 Univariate analysis of potential prognostic factors for overall survival in patients who underwent surgical or local ablative resection of renal-cell carcinoma liver metastases

\begin{tabular}{|c|c|c|c|}
\hline Prognostic factor & $\begin{array}{l}\text { No. of } \\
\text { patients }\end{array}$ & $\begin{array}{l}\text { Median survival } \\
\text { (months) }\end{array}$ & $P$ value \\
\hline Age & & & 0.37 \\
\hline$\leq 60$ years & 16 & 27 & \\
\hline$>60$ years & 17 & 33 & \\
\hline Sex & & & 0.38 \\
\hline Male & 16 & 23 & \\
\hline Female & 17 & 33 & \\
\hline Primary tumor side ${ }^{a}$ & & & 0.95 \\
\hline Left & 14 & 27 & \\
\hline Right & 17 & $>33$ & \\
\hline \multicolumn{4}{|l|}{ Liver metastases } \\
\hline Timing & & & 0.03 \\
\hline Synchronous & 10 & 18 & \\
\hline Metachronous & 23 & $>37$ & \\
\hline Disease-free interval & & & 0.051 \\
\hline$\leq 24$ months & 17 & 22 & \\
\hline$>24$ months & 16 & $>37$ & \\
\hline $\begin{array}{l}\text { Size of largest } \\
\text { metastasis }\end{array}$ & & & 0.54 \\
\hline$\leq 50 \mathrm{~mm}$ & 18 & $>33$ & \\
\hline$>50 \mathrm{~mm}$ & 12 & 24 & \\
\hline Number of metastases & & & 0.93 \\
\hline Solitary & 19 & 27 & \\
\hline Multiple & 14 & $>33$ & \\
\hline Extrahepatic disease & & & 0.28 \\
\hline Present & 11 & 27 & \\
\hline Absent & 22 & $>37$ & \\
\hline Resection margin & & & $\leq 0.001$ \\
\hline $\begin{array}{l}\text { Radical resection } \\
\text { (R0) }\end{array}$ & $19^{\mathrm{a}}$ & 37 & \\
\hline $\begin{array}{l}\text { Irradical resection } \\
(\mathrm{R} 1 / \mathrm{R} 2)\end{array}$ & 6 & 9 & \\
\hline
\end{tabular}

Data from patients who underwent radiofrequency ablation were not analyzed

${ }^{\text {a }}$ Data were not available for all patients

Overall 1-, 3-, and 5-year survival rates were 78, 47, and $43 \%$, respectively (Fig. 1). The median overall survival was 33 (4-224) months.

\section{Univariate Analysis of Prognostic Factors}

In the univariate analysis, two factors showed statistically significant influence on overall survival (Table 2). None of the patients with an incomplete resection (R1 or R2) survived longer than 23 months, in contrast to patients with a complete resection (R0), who had a median survival of 37 months $(P<0.001)$, as shown in Fig. 2. Patients



FIG. 2 Overall survival according to resection margins $(P<0.001)$. Patient who underwent radiofrequency ablation were excluded from this analysis

with synchronous metastases had a statistically significantly $(P=0.03)$ shorter survival than patients with metachronous metastases (Fig. 3). This effect slightly diminished when we compared the median overall survival of patients with a disease-free interval of less than 24 months and those with an interval between primary tumor and liver metastases of more than 24 months; the effect was not statistically significant $(P=0.051)$. Because of the heterogeneity of the adjuvant therapy, this was not analyzed as a prognostic factor. Age and sex of the patient ( $\leq 60$ vs. $>60$ years), site of the primary tumor, number of liver metastases, or size of the largest metastasis had no

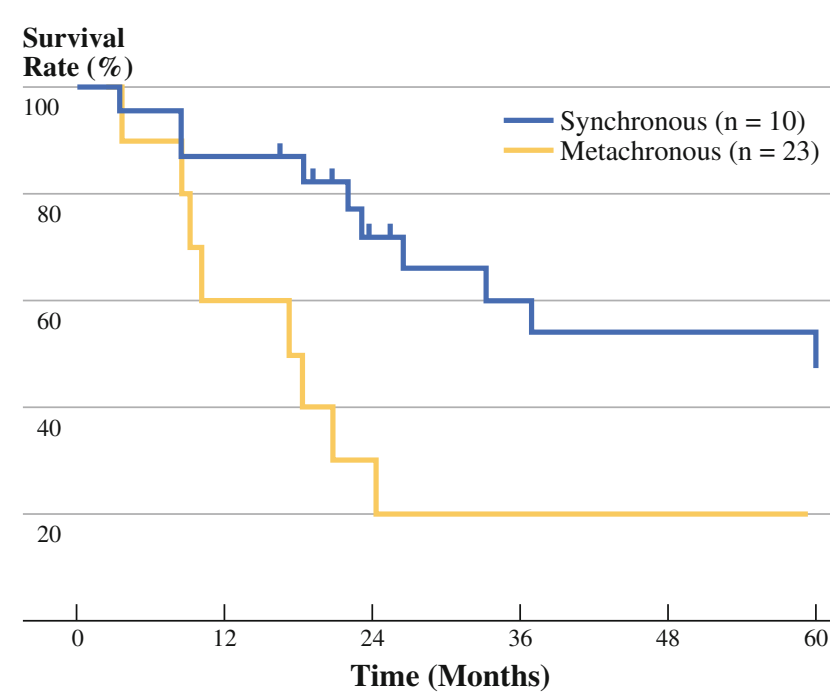

FIG. 3 Overall survival according to the timing of resection of renalcell carcinoma liver metastases $(P=0.03)$ 
statistically significant influence on overall survival (Table 2).

\section{DISCUSSION}

Patients with RCCLM generally have a particularly poor prognosis, which is even worse than patients with RCC metastases to other organs, such as lungs and bone. ${ }^{13}$ In the series of Suppiah et al., the median survival of 186 untreated patients with hepatic RCC metastases was only 7.8 months. ${ }^{13}$ However, the present population-based study demonstrates that a selected subgroup of patients with RCCLM can be offered the possibility of long-term survival by surgical intervention, either resection or local ablation. Five-year survival of $43 \%$ as found in the present study is substantially better than the approximately $10 \%$ survival after 1 year reported in the whole group of patients with RCCLM. ${ }^{14,15}$

Data regarding the efficacy of surgical treatment of RCCLM are rarely reported. In a survival analysis based on 15 reports by Aloia et al., 2-year survival was $40 \% .^{9}$ Besides this review including 64 patients, two other studies have been published. ${ }^{16,17}$ Thelen et al. described their single-institution experience in 31 patients who underwent liver resection for RCC metastases with an overall 5-year survival of $38 \% .{ }^{17}$ Adam et al. described a series of 1452 patients with noncolorectal, nonneuroendocrine hepatic metastases, of whom 85 had a primary RCC. ${ }^{16}$ Median overall survival was 36 months, with a 5-year survival rate of $38 \%$.

The reported survival rates in the present study are superior to the results of older series reviewed by Alioa et al., and comparable to the recently published series from Adam et al. and Thelen et al. ${ }^{9,16,17}$ The improved survival rates in time could well be explained by better patient selection, surgical technique, and perioperative care. Advancements in imaging technology resulting in more adequate staging, and better appreciation of tumor and patient characteristics that influence prognosis have probably contributed to the improved patient selection. Technical improvements in liver surgery during the past decades and improvement of perioperative care have resulted in a safer approach to both minor and major resections.

Prognostic factors predicting long-term survival after resection of RCCLM as described in previous series included male sex, a maximum metastasis diameter of $\leq 5 \mathrm{~cm}$, primary tumor localization in the left kidney, disease-free interval of $>24$ months, and tumor-negative resection margins. ${ }^{17}$ The aim of determining such prognostic factors is to establish selection criteria for resection. In our series, only metachronous metastases and radical resection had a positive impact on overall survival in univariate analysis. Surprisingly, extrahepatic disease had no statistically significant impact on survival, with a trend toward improved survival, although patient numbers are small. This finding is in agreement with data from Alioa et al. ${ }^{9}$ We assume that these patients have only slowly progressive disease with relatively long disease-free intervals between each distant metastasis. Such patients with indolent biological behavior of RCC make them ideal candidates for sequential metastasectomies. Therefore, selection bias is probably the most important explanation for this contradictory finding.

We involved all centers performing liver surgery in the Netherlands. Furthermore, we did a search in the nationwide histopathology database, PALGA, in which all data on resection specimens in the Netherlands are archived. In this manner, we believe that we reliably retrieved data from all patients who underwent surgical treatment for hepatic metastases from RCC in the last 19 years in the Netherlands. This fact addresses another interesting point of this study. From data of the Dutch cancer registry, we know that 30,000 patients were diagnosed with RCC in the study period. ${ }^{1}$ On the basis of the approximately 10 to $20 \%$ of patients with RCC who ultimately developed liver metastases, we can estimate the total number of patients with RCCLM during this time period in the Netherlands. ${ }^{18-21}$ In the last 19 years, approximately $3000-6000$ patients (10 to $20 \%$ of 29,627 ) had hepatic metastases due to RCC. In this particular time period, we identified 33 patients who where surgically treated, which indicates that approximately 0.5 to $1 \%$ of the patients underwent surgical intervention. This emphasizes once more the remarkably small proportion of these patients who were treated surgically. The question remains whether it is only this small proportion of patients having an indication for surgical treatment, or whether some patients are not referred by urologists or medical oncologists for treatment, not being aware of the potential impact on survival.

We realize the limitations of this study. Data were obtained from a complete but relatively small group of patients, limiting analysis on prognostic factors because of wide confidence intervals and hampering adequate multivariate analysis. Data were retrieved over a long study period (19 years), during which many novel techniques in imaging, perioperative care, and liver surgery were introduced, as described above. Finally, data were retrieved from 14 hospitals in a retrospective way, with its inherent methodological drawbacks. Hence, care must be taken in drawing strong conclusions from the available data. On the other hand, the relatively good survival rates, despite a large heterogeneity in selection criteria of the different hospitals, together with improvements in liver surgery in 
the last decade, suggest that even better survival rates could be reached after adequate patient selection.

The survival rates presented in this study and the results of previous studies compare well with the results of hepatic resection for colorectal metastases. ${ }^{9,16,17}$ Likewise, these survival rates are also certainly not inferior to results after resection of pulmonary metastases in patients with RCC. The outcomes of surgery on RCC metastases to the lungs have been well investigated. Several relatively large series, although retrospective and nonrandomized, emphasize a survival benefit, and the possibility of long-term survival (up to $37 \%$ 5-year survival rate) after radical resection in selected patients with relatively few complications. ${ }^{7,22,23}$

An aggressive surgical approach to these pulmonary metastases, in which a radical resection can be achieved, is currently considered as the appropriate treatment. The future will tell whether surgical treatment for RCCLM will achieve the same status as in treatment of RCC lung metastases. Although molecularly targeted therapies have resulted in marked survival benefit in metastatic RCC, they do not provide the possibility of long-term survival. The results of this study, and of comparable reports in literature, presume a wider indication for liver resection in patients with RCC, and deny the suggestion that patients with RCCLM cannot be cured. Future research should also further define the role of molecularly targeted therapy in possible (neo)adjuvant therapies.

In conclusion, surgical treatment of hepatic metastases from RCC is only performed in approximately $1 \%$ of patients. Data from this study, in accordance with data from almost 150 patients reported in the literature, suggest that surgical treatment can provide favorable survival rates, with a 5-year survival of $43 \%$. The present data on survival rates after surgery, combined with the unavailability of effective systemic therapies, justify an aggressive surgical approach in patients with hepatic metastases from RCC when a margin-negative resection can be obtained.

CONFLICT OF INTEREST The authors declare no conflict of interest.

OPEN ACCESS This article is distributed under the terms of the Creative Commons Attribution Noncommercial License which permits any noncommercial use, distribution, and reproduction in any medium, provided the original author(s) and source are credited.

\section{APPENDIX}

Collaborators of the Dutch Study Group for Liver Surgery includes K. P. de Jong, University Medical Center Groningen (UMCG), Groningen; A. M. Rijken, Amphia Hospital, Breda; M. P. van den Tol, VU Medical Centre, Amsterdam; R. A. Tollenaar, Leiden University Medical
Center, Leiden; J. R. van der Sijp, Medisch Centrum Haaglanden, the Hague; E. J. Hesselink, Gelre Ziekenhuizen, Apeldoorn; R. M. van Dam, Maastricht University Medical Center; J. M. Klaase, Medisch Spectrum Twente, Enschede; W. Vening, Máxima Medical Center, Veldhoven; J. A. Van Kollenburg, Maasland Hospital, Sittard.

\section{REFERENCES}

1. Association of Comprehensive Cancer Centres. Incidence of renal cell carcinoma. 2010. http://www.ikcnet.nl/cijfers/index. php?taal=en\&frequentiemaat $=1$. Accessed 28 July 2010.

2. Mickisch GH, Garin A, van Poppel H, de Prijck L, Sylvester R, European Organisation for Research and Treatment of Cancer (EORTC) Genitourinary Group. Radical nephrectomy plus interferon-alfa-based immunotherapy compared with interferon alfa alone in metastatic renal-cell carcinoma: a randomised trial. Lancet 2001;358(9286):966-70.

3. Gupta K, Miller JD, Li JZ, Russell MW, Charbonneau C. Epidemiologic and socioeconomic burden of metastatic renal cell carcinoma (mRCC): a literature review. Cancer Treat Rev. 2008;34:193-205.

4. DiBiase SJ, Valicenti RK, Schultz D, et al. Palliative irradiation for focally symptomatic metastatic renal cell carcinoma: support for dose escalation based on a biological model. J Urol. 1997; 158(3 Pt 1):746-9.

5. Escudier B, Eisen T, Stadler WM, et al. Sorafenib for treatment of renal cell carcinoma: final efficacy and safety results of the phase III treatment approaches in renal cancer global evaluation trial. J Clin Oncol. 2009;27:3312-8.

6. Motzer RJ, Hutson TE, Tomczak P, et al. Overall survival and updated results for sunitinib compared with interferon alfa in patients with metastatic renal cell carcinoma. J Clin Oncol. 2009; 27:3584-90.

7. Pfannschmidt J, Hoffmann H, Muley T, et al. Prognostic factors for survival after pulmonary resection of metastatic renal cell carcinoma. Ann Thorac Surg. 2002;74:1653-7.

8. Dineen MK, Pastore RD, Emrich LJ, Huben RP. Results of surgical treatment of renal cell carcinoma with solitary metastasis. J Urol. 1988;140:277-9.

9. Aloia TA, Adam R, Azoulay D, Bismuth H, Castaing D. Outcome following hepatic resection of metastatic renal tumors: the Paul Brousse Hospital experience. HPB (Oxford). 2006;8:100-5.

10. Casparie M, Tiebosch AT, Burger G, et al. Pathology databanking and biobanking in The Netherlands, a central role for PALGA, the nationwide histopathology and cytopathology data network and archive. Cell Oncol. 2007;29:19-24.

11. Gouw AS, de Jong KP. Images in hepatology: "cholangitis carcinomatosa." J Hepatol 1997;27:755.

12. Dindo D, Demartines N, Clavien PA. Classification of surgical complications: a new proposal with evaluation in a cohort of 6336 patients and results of a survey. Ann Surg. 2004;240: 205-13.

13. Suppiah R, Shaheen PE, Elson P, et al. Thrombocytosis as a prognostic factor for survival in patients with metastatic renal cell carcinoma. Cancer. 2006;107:1793-800.

14. Maldazys JD, deKernion JB. Prognostic factors in metastatic renal carcinoma. J Urol. 1986;136:376-9.

15. Motzer RJ, Bander NH, Nanus DM. Renal-cell carcinoma. N Engl J Med. 1996;335:865-75.

16. Adam R, Chiche L, Aloia T, et al. Hepatic resection for noncolorectal nonendocrine liver metastases: analysis of 1,452 patients 
and development of a prognostic model. Ann Surg. 2006;244: 524-35.

17. Thelen A, Jonas S, Benckert C, et al. Liver resection for metastases from renal cell carcinoma. World J Surg. 2007;31:802-7.

18. Gleave ME, Elhilali M, Fradet Y, et al. Interferon gamma-1b compared with placebo in metastatic renal-cell carcinoma. Canadian Urologic Oncology Group. N Engl J Med. 1998;338: 1265-71.

19. Motzer RJ, Mazumdar M, Bacik J, et al. Survival and prognostic stratification of 670 patients with advanced renal cell carcinoma. J Clin Oncol. 1999;17:2530-40.
20. Ritchie AW, Chisholm GD. The natural history of renal carcinoma. Semin Oncol. 1983;10:390-400.

21. Yang JC, Haworth L, Sherry RM, et al. A randomized trial of bevacizumab, an anti-vascular endothelial growth factor antibody, for metastatic renal cancer. $N$ Engl J Med. 2003;349: 427-34.

22. Kavolius JP, Mastorakos DP, Pavlovich C, et al. Resection of metastatic renal cell carcinoma. J Clin Oncol. 1998;16:2261-6.

23. van der Poel HG, Roukema JA, Horenblas S, van Geel AN, Debruyne FM. Metastasectomy in renal cell carcinoma: a multicenter retrospective analysis. Eur Urol. 1999;35:197-203. 